\title{
Evaluation of Carrying Position for Babies
}

\author{
Mrs.J.Rajalakshmi, Dr.Kebede Legesse, \\ Bsc, Msc nursing, lecturer in ambo university \\ $M D$, dean, medical science department, ambo university
}

Keywords
-Introduction
-Difference
-Rock -a-baby-
Infant spine
development
-Science based
view $\quad$-Learning to carry
a baby $\quad$-Different methods
of carrying a baby
-Nine reasons not
to carry

\section{Introduction}

Modern notions in biology have also led to the human infant being classified as belonging to the "carried type of young" (i.e., infants that are typically carried on the bodies of their mothers), in contrast to the offspring of other mammals that are generally left in a hidden place (i.e., nested or cached. This view is based on evolutionary, particularly anatomical, considerations, and is substantiated by young infants' typical reactions when parted from their caregivers. human infants still display many striking characteristics of a carried young. Like a gorilla baby, the human infant, when lying on the back, frequently assumes a position where both legs are flexed and abducted (Figure 1). This position is also adopted when the lying or sitting child is lifted up (Figure 2) and allows the child to be placed astride the caregiver's hip, nestled against the carrier's body
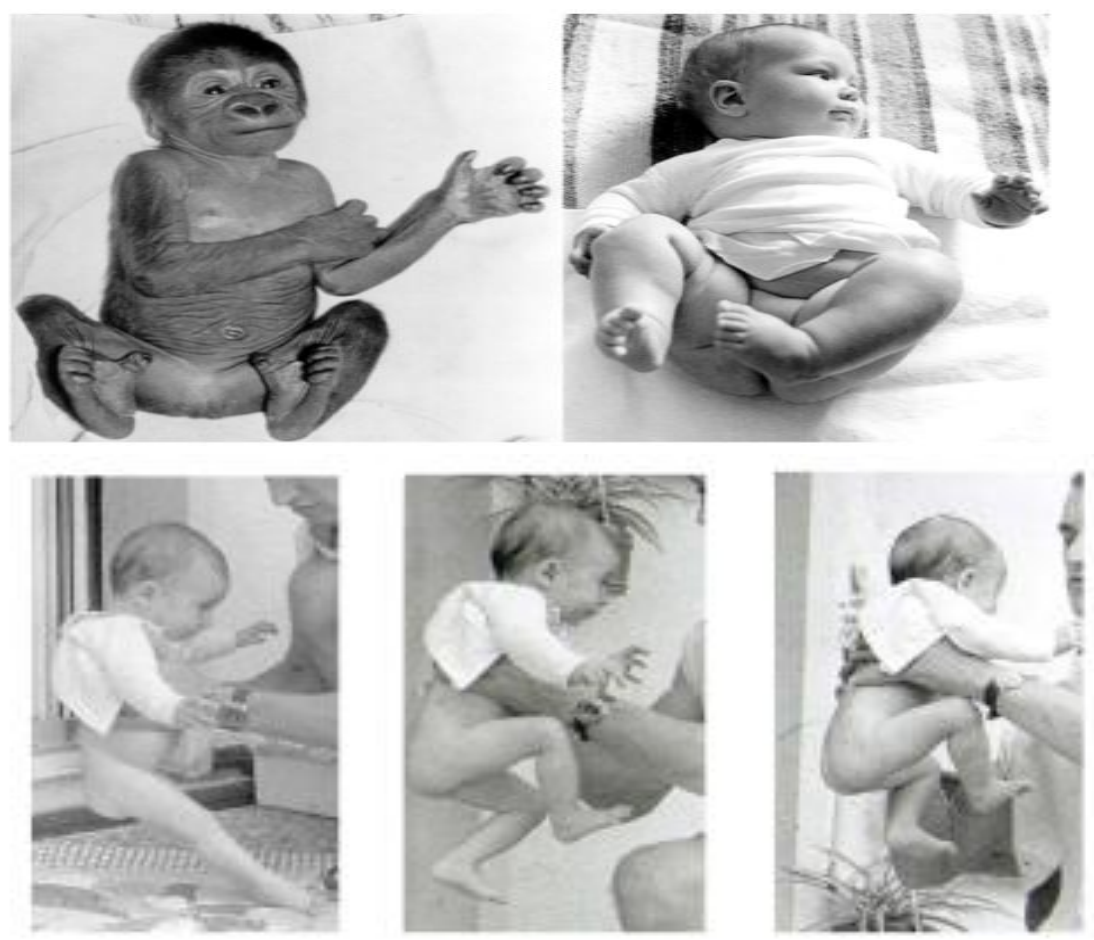


\section{Difference Between Baby Carrying By Foraging, Nomadic Peoples,}

Horticulturalists.
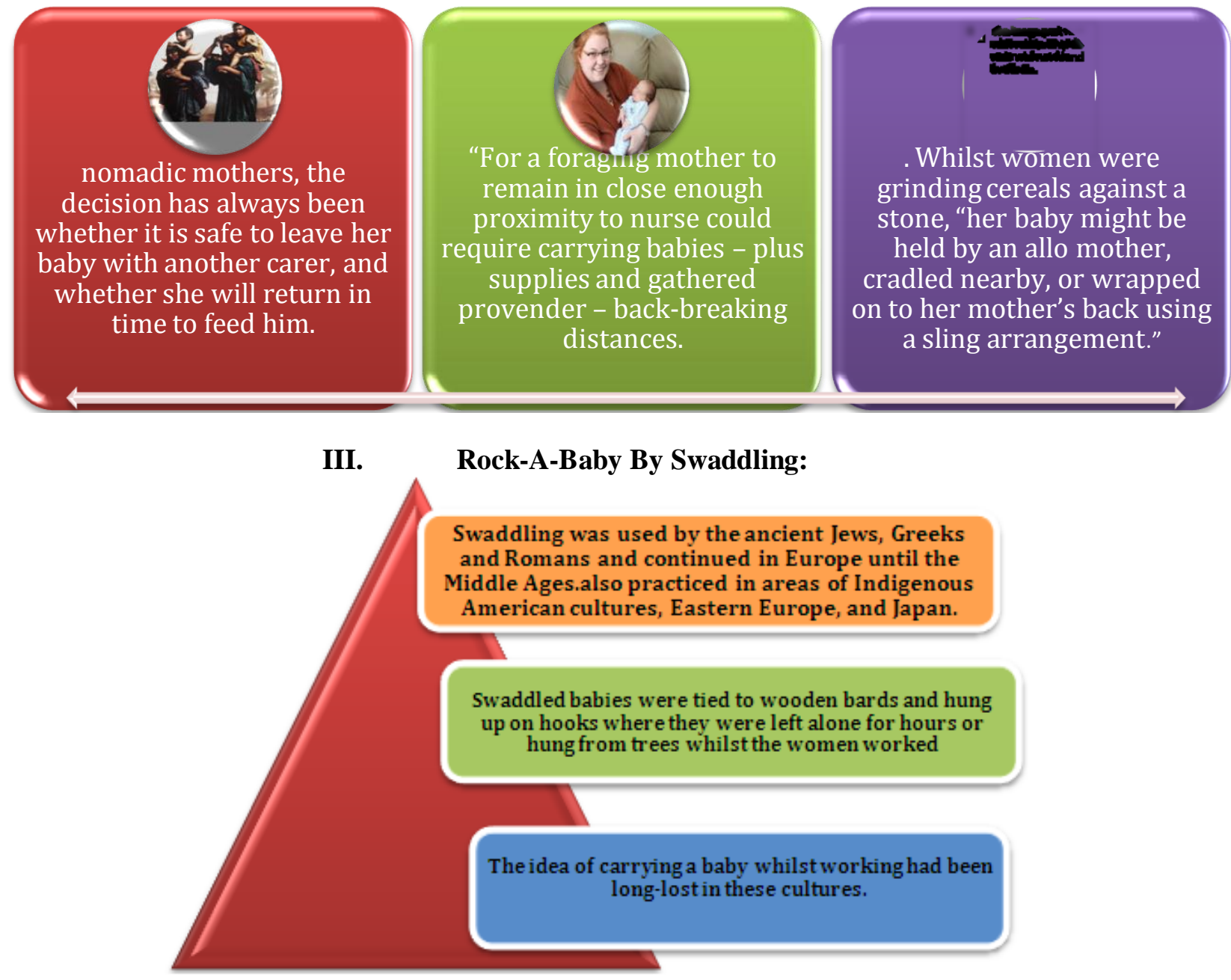

\subsection{Infant spine development:}

Our spine is not perfectly straight, even though it may appear so from the front or back. When you look at a person from the side, four slight curves are visible, forming an elongated " $\mathrm{S}$ " shape. These curves help keep us flexible and balanced. At birth, babies are in a state of flexion, still curled up, with their spine in a natural long c-shaped (convex) curve. At first, a baby does not have the strength to hold his head up, nor the balancing curves in his spine to do so. But gradually as the muscles in his neck get stronger, he begins to lift his heavy head against gravity, and a curve starts to develop in his neck (the cervical curve) to help balance his head. 

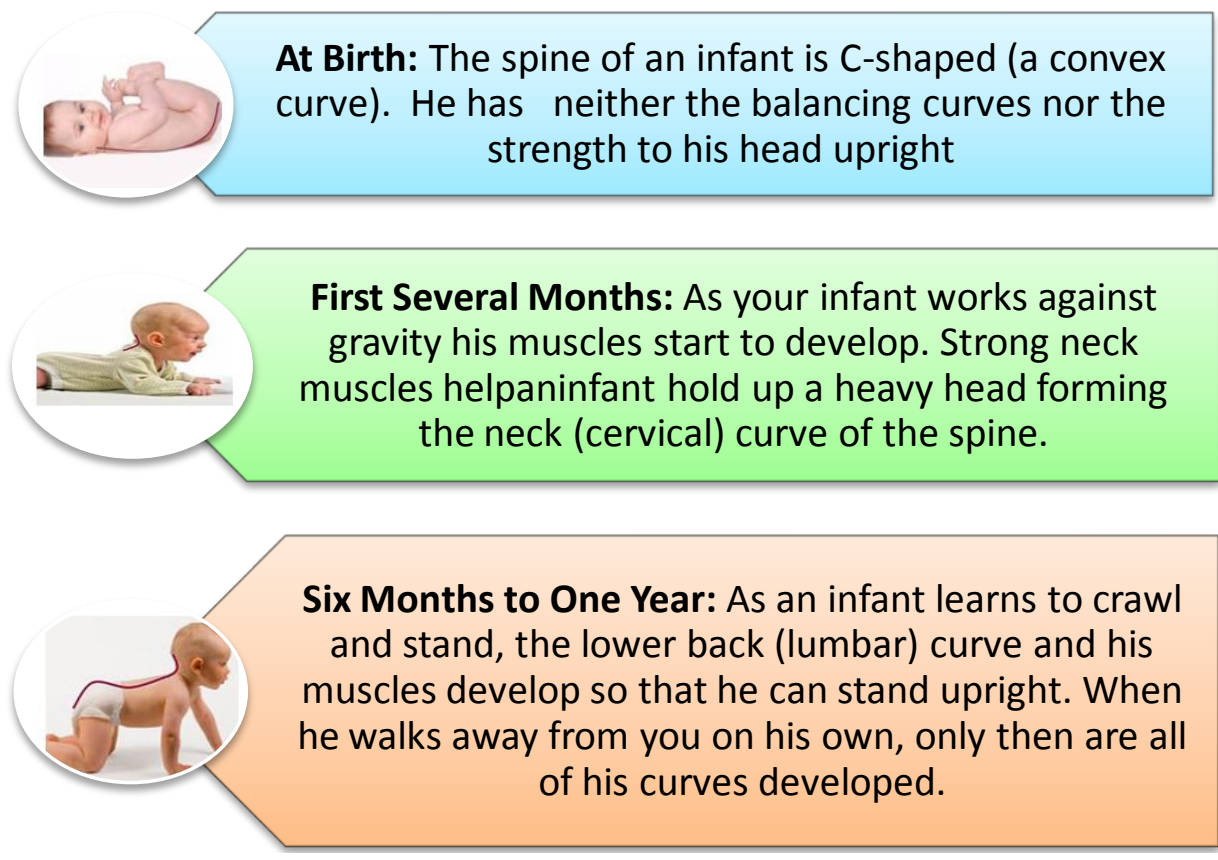

\section{Ages \& Stages: A Science-Based View On Baby Carrying Positions}

\subsection{Need For Brain Stimulation:}

The great amount of research done on the baby's developing brain is indeed how vital appropriate stimulation is. When the baby is born, the number of neurons in its brain corresponds to adults'. However, what is missing is the mindboggling amount of connections that will eventually shape that particular baby's personality and intelligence. These connections are formed by and are utterly dependent on the type of stimuli that the baby receives from the outside world. Every experience the baby is exposed to will activate some part of the brain's neurons. The more frequently a given experience occurs, the stronger the connections between the activated neurons become. As neuroscientists sometimes say: "Cells that fire together, wire together." we need to look at the major developmental phases that a baby goes through in her first year.

\subsection{Three Stages Of Baby's Development:}

In the first few months after birth, the baby's main developmental task is adaption to life outside the womb. A variety of basic functions have to be mastered: suckling, digesting, breathing, vocalizing, defecating, and seeing.

At around 2-3 months of age, the baby begins to actively seek out social exchanges with adults, using its glance and smile to attract attention and initiate conversations or playful episodes. This marks the beginning of a phase, lasting about three or four months (age 2-6 months) where the baby is intensely interested in the human face.

From around 6 months of age, with the emergence of eye-hand coordination, the baby's attention gradually switches towards the world of objects.. Their primary role becomes to help the baby decipher and interpret ambiguous situations where the baby feels insecure.

\section{Learning To Carry Your Baby:}

1. choosing the carrying methods suitable for his or her age.

2. your baby should be able to rest on his buttocks with his legs apart and raised in what is called a "frog" position.

3. His back should be bent and not straight, and his head should rest on your chest.

4. always carry your baby against your abdomen, facing you, or on your back.

5. The position looking out onto the world allows him to look at everything but it does not respect the curve of his back

6. If you get backache, your wrap is no doubt tied incorrectly or your baby carrier is not adjusted correctly

7. baby carrying requires a few days to a few weeks of practice for you and your baby to get used to and become perfectly at ease with.

8. It helps some babies to breastfeed better. Some babies, particularly those who are tense or tend to arch their backs, breastfeed better while moving. 


\subsection{Advantages:}

1. Carrying method that reduces crying and colic of baby . A 1986 study of 99 mother-infant pairs (reported in Pediatrics) showed that carrying babies at least three hours a day reduces crying and fussing $43 \%$ during the day and $51 \%$ at night.

2. It enhances learning. Carried babies have enhanced visual and auditory alertness, and increased "quiet alertness" times.

3. Carrying a baby promotes cognitive development and speech development, since babies are exposed to more experiences and conversations.

4. Carrying your baby promotes bonding and enhances parents' feelings of competence. A higher frequency of feeding and touching stimulates mothering hormones, and frequent carrying encourages and speeds the development of a mutual reading of each other's cues.

5. When infants are held upright, The force of gravity is a positive element in infant development. It allows them to learn to hold their heads up and keep their bodies balanced.

6. Carrying a young infant in the horizontal position with legs together in a baby carrier (like a sling or a wrap) provides adequate spinal support

7. Upright baby carriers that support the legs, carrying a baby as a mother naturally would in arms, do not compromise a baby's spine or hips. When an infant's legs are flexed and straddled, the instinctive position that his little body assumes when picked up, the head of his femur (bone of the thigh) fills out the hip socket (acetabulum)

8. Proponents of horizontal positioning in early infancy may be concerned with whether the infant actually receives adequate levels of oxygen while being carried by mother

9. carried babies receive a lot of vestibular stimulation, whereas lying babies do not. Our vestibular system helps us out with our sense of balance and our security in space. When a mother holds her baby, the baby moves back and forth with mom's walking, and side to side from her swaying or rocking.

10. Vertical positioning as optimal in infants makes perfect sense. Think, if the infants spend horizontal-flat on their back in a crib or a buggy. Might this affect their alertness.

\section{Different Methods Of Carrying A Baby:}

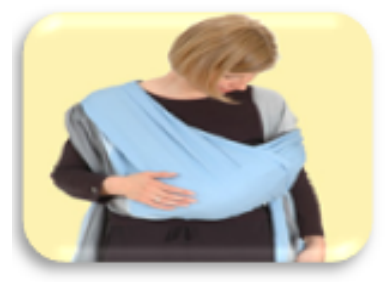

cradle-carry- is the ideal way of rocking to sleep a

new-born baby while doing other things at the same

time. When the baby is asleep you can gently lay it

down together with the sling without waking it.

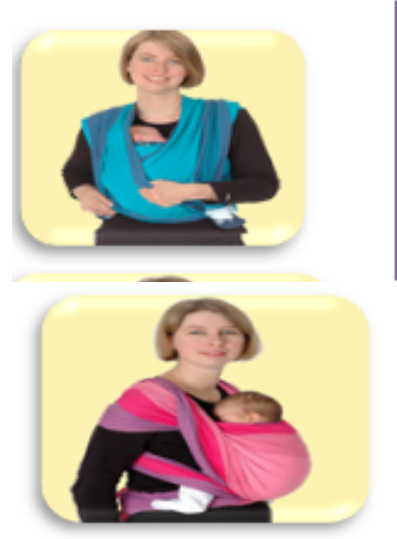

Cross carry- It gives even better support to your

child because it uses a third strip of fabric, which crosses the baby's back

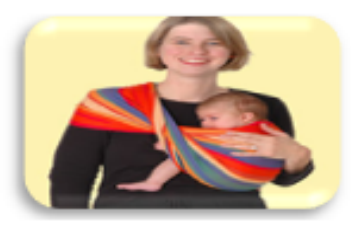

kangaroo-carry -is another way of carrying your child on your front. It warm the baby and promote bonding

Hip carry-Carrying a child on the hip without a sling strains the arm and makes it tired. weight of the child equally between hip and shoulder. Apart from this the baby's back is supported better 


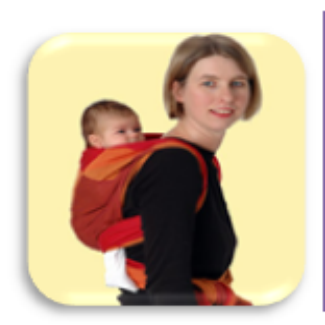

rucksack-carry-This method is not only ergonomically

better for you, but bigger children especially enjoy the view

from this more open position. You can use the "rucksack-

carry" as soon as your child is able to hold its head firmly by

itself.

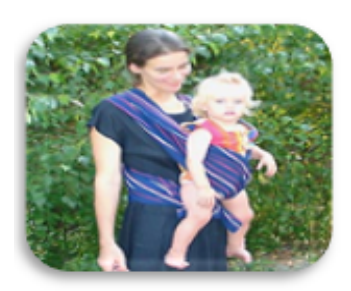

Front carry-Some children like to be carried facing

outwards. You can do this, of course, with this sling, as well.

However not recommend this way of carrying - neither in the

sling nor in any other carrying-device. becoming dangerous

\subsection{Nine Reasons Not To Carry Your Baby Facing Out:}

1. does not support your baby's legs.

2. makes it tough for the wearer to carry the baby.

3. places your baby in an arched or hollow back position which places pressure on the spine, groin and may chafe the inner thighs of your baby.

4. may over stimulate your baby.

5. doesn't support the head or the neck leads to Positional asphyxia

6. makes thermoregulation more difficult.

7. makes it harder to respond to baby's cues.

8. throws off baby's center of gravity.

9. may not be so wonderful on your back either.

\section{Conclusion}

In conclusion, conventional baby carrying may reduce the amount of crying. If your baby has colic or you would like to preempt the onset of colic, you could practice carrying in the same manner as many indigenous people, with skin-to-skin contact, just make sure that you are there for your baby, and that you have someone who is there for you as well, so you can go through this challenging phase with a strengthened love for your baby and for one another. Colic will pass for your baby.

\section{Reference:}

[1]. Alvarez M. Caregiving and Early Infant Crying in a Danish Community. Developmental and Behavioral Pediatrics Vol. 25, No. 2, April 2004

[2]. Barr RG, McMullan SJ, Spiess H, Leduc DG, Jaremko, J, Barfield R, Francouer E \& Hunziker UA. Carrying as Colic Therapy: A Randomized Controlled Trial. Pediatrics, Vol 87, 5 1991. P. 623-630

[3]. Bennedbaek O, Viktor J, Carlsen KS, Roed H, Vinding H, Lundbye-Christensen S. Infants with colic. A heterogenous group possible to cure? Treatment by pediatric consultation followed by a study of the effect of zone therapy on incurable colic. Ugeskr Laeger. 2001 Jul 2; 163(27):3773-8. (In Danish, abstract available in English)

[4]. Bowen JR \& Kotzias-Neto A. 2006. Developmental dysplasia of the hip. Data Trace Publishing Company. ISBN. 1-57400-108-6.

[5]. Hewlett B, Lamb ME, Shannon D, Leyendecker B \& Scholmerich A. Culture and Early Infancy Among Central African Foragers and Farmers. Developmental Psychology 1998 ifcl. 34, No. 4, 653-661

[6]. Hunziker UA \& Barr RG. Increased Carrying Reduces Crying: A Randomized Controlled Trial. Pediatrics, Vol 75, 5 1986. P. 641 648.

[7]. Landgren K, Kvorning N, Hallstrom I. Acupuncture reduces crying in infants with infantile colic: a randomized controlled, blind clinical study. Acupuncture Med 2010; 28:174-179. doi:10.1136/aim.2010.002394

[8]. Kirkilionis. E. 1997. Die Grundbedürfnisse des Säuglings und deren medizinische Aspekte. Teil 1. Notabene Medici 2, p. 61-66.

[9]. Kirkilionis. E. 1997. Die Grundbedürfnisse des Säuglings und deren medizinische Aspekte. Teil 2. Notabene Medici 3, p. 117-121.

[10]. Mahan ST \& Kasser JR. 2008. Does swaddling influence developmental dysplasia of the hip? Pediatrics 121;177-178

[11]. Salter R. 1968. Etiology, pathogenesis and possible prevention of congenital dislocation of the hip. Can. Med. Assoc. 98; 933-945

[12]. St James-Roberts I. Infant Crying and Sleeping: Helping Parents to Prevent and Manage Problems. Prim Care Clin Office Pract 35 (2008) 547-567

[13]. St James-Roberts I, Alvarez M, Csipke E, Abramsky T, Goodwin J \& Sorgenfrei E. Infant Crying and Sleeping in London, Copenhagen and When Parents Adopt a "Proximal" Form of Care. Pediatrics 2006; 117; e1146-e1155

[14]. Wessel MA, Cobb JC, Jackson EB, Harris GS, Detwiler AC. Paroxysmal fussing in infancy, sometimes called colic. Pediatrics 1954, 14:421-435.

[15]. International Hip Dysplasia Institute. http://www.hipdysplasia.org/default.aspx

[16]. Internet resources: http://www.somatics.de/TraumaSomatics07.pdf 